Article

\title{
Experimental and Numerical Analysis of the Mechanical Properties of a Pretreated Shape Memory Alloy Wire in a Self-Centering Steel Brace
}

\author{
Bo Zhang ${ }^{1,2}$, Sizhi Zeng ${ }^{3}$, Fenghua Tang ${ }^{1}$, Shujun $\mathrm{Hu}{ }^{1, *} \mathbb{C}$, Qiang Zhou ${ }^{1}$ and Yigang Jia ${ }^{1,2}$ \\ 1 School of Civil Engineering and Architecture, Nanchang University, Nanchang 330031, China; \\ zhangbo_tujian@nerin.com (B.Z.); tfh2450748@163.com (F.T.); zhouqiang@ncu.edu.cn (Q.Z.); \\ yigang_jia@126.com (Y.J.) \\ 2 Design and Research Institute, Nanchang University, Nanchang 330031, China \\ 3 Zhongmei Engineering Group Ltd., Nanchang 330001, China; zhihui_196@163.com \\ * Correspondence: hushujun@ncu.edu.cn; Tel.: +86-155-7918-3858
}

check for

updates

Citation: Zhang, B.; Zeng, S.; Tang, F.; $\mathrm{Hu}, \mathrm{S}$.; Zhou, Q.; Jia, Y. Experimental and Numerical Analysis of the

Mechanical Properties of a Pretreated Shape Memory Alloy Wire in a Self-Centering Steel Brace. Processes 2021, 9, 80. https://doi.org/10.3390/ pr9010080

Received: 12 November 2020 Accepted: 14 December 2020 Published: 1 January 2021

Publisher's Note: MDPI stays neutral with regard to jurisdictional clai$\mathrm{ms}$ in published maps and institutional affiliations.

Copyright: (C) 2021 by the authors. Licensee MDPI, Basel, Switzerland. This article is an open access article distributed under the terms and conditions of the Creative Commons Attribution (CC BY) license (https:// creativecommons.org/licenses/by/ $4.0 /)$.

\begin{abstract}
As a stimulus-sensitive material, the difference in composition, fabrication process, and influencing factors will have a great effect on the mechanical properties of a superelastic Ni-Ti shape memory alloy (SMA) wire, so the seismic performance of the self-centering steel brace with SMA wires may not be accurately obtained. In this paper, the cyclic tensile tests of a kind of SMA wire with a $1 \mathrm{~mm}$ diameter and special element composition were tested under multi-working conditions, which were pretreated by first tensioning to the 0.06 strain amplitude for 40 cycles, so the mechanical properties of the pretreated SMA wires can be simulated in detail. The accuracy of the numerical results with the improved model of Graesser's theory was verified by a comparison to the experimental results. The experimental results show that the number of cycles has no significant effect on the mechanical properties of SMA wires after a certain number of cyclic tensile training. With the loading rate increasing, the pinch effect of the hysteresis curves will be enlarged, while the effective elastic modulus and slope of the transformation stresses in the process of loading and unloading are also increased, and the maximum energy dissipation capacity of the SMA wires appears at a loading rate of $0.675 \mathrm{~mm} / \mathrm{s}$. Moreover, with the initial strain increasing, the slope of the transformation stresses in the process of loading is increased, while the effective elastic modulus and slope of the transformation stresses in the process of unloading are decreased, and the maximum energy dissipation capacity appears at the initial strain of 0.0075. In addition, a good agreement between the test and numerical results is obtained by comparing with the hysteresis curves and energy dissipation values, so the numerical model is useful to predict the stress-strain relations at different stages. The test and numerical results will also provide a basis for the design of corresponding self-centering steel dampers.
\end{abstract}

Keywords: shape memory alloy (SMA); strain amplitude; loading rate; initial strain; energy dissipation capacity

\section{Introduction}

Shape memory alloy (SMA) is a kind of smart materials that can return to their original shape or original size after loading and unloading when subjected to cyclic loading, and this transformation phenomenon existing in the Martensite and Austenite phases is known as the shape memory effect [1,2]. After a number of preloading cycles, SMA can produce ideal flag shape hysteresis without residual deformation [3]. The superelasticity of SMA with strain recovery (up to 0.08 strain) is promoted spontaneously upon unloading without any extra force, and the flag shape hysteresis obtained by SMA can dissipate the seismic energy when under loading [4,5].

No collapse under rare earthquakes can be easily achieved in the structural design [6-9], but the buildings still may be prone to plastic deformation and residual 
deformation after earthquakes, which will cause the repair work to be very difficult [10-13]. Due to the superelasticity and good energy dissipation, SMA has gained increasing attention in the field of civil engineering, and a variety of self-centering dampers with SMAs that can reduce the residual deformations and increase the energy dissipation capacity of buildings have been developed. Xue [14] investigated an innovative SMA incorporated friction damper by combining the SMA wires with the friction damper. Ren [15] conducted experimental studies on a new shape memory alloy friction damper, consisting of the superelastic SMA element and the friction element. Qiu [4] proposed an SMA-based brace with appealing superelasticity and energy dissipation capacity, which was utilized to control the seismic performance of steel frames. Liu [16] studied the mechanical property of an innovative re-centering shape memory alloy shearing lead damper, consisting of an SMA, shearing leads, and springs. Huang [17] developed an innovative re-centering deformation-amplified SMA damper (RDASD) by utilizing the superelastic property of the SMA materials. $\mathrm{Hu}$ [18] indicated that a new self-centering brace with low friction and SMA can have excellent seismic performance. The mechanical property of the SMA wires is one of the key factors to get the ideal energy dissipation capacity of the self-centering dampers without residual deformations. However, as a sensitive material, the difference in composition, fabrication process, and influencing factors for SMA wires will also have a great effect on the mechanical properties.

The influencing factors of a specific SMA wire mainly include the number of cycles, strain amplitude, loading rate, initial strain, and temperature, etc. For example, Ren [15] studied the superelastic deformation behavior of a Ni-Ti SMA subjected to cyclic loading under variable amplitudes; Lin [19] dealt with the effect of the number of cycles, strain amplitude, and loading rate on the mechanical behaviors of SMA wires; Yan [20] investigated the mechanical parameters of SMAs with the effects of number of cycles, strain amplitude, and loading rate; Zhou [21] conducted a cyclic tension loading test of the number of cycles, loading rate, and initial strain on a pre-tensioned $0.5-\mathrm{mm}$ diameter Ni-Ti SMA; and Lin [22] carried out the fatigue test of an SMA wire by changing the temperature. In addition, the main elements of a superelastic Ni-Ti SMA wire are the nickel element $(\mathrm{Ni})$ and titanium element (Ti), but the SMA used in the previous analysis may have a different composition for different manufactures, e.g., the atomic mass ratios of the $\mathrm{Ni}$ and $\mathrm{Ti}$ were $55.800 \%$ and 44.200 [19], 55.980\% and $43.906 \%$ [22], 56.050\% and $43.95 \%$ [23], and $50.900 \%$ and $49.100 \%$ [24], respectively. The SMA with a difference in composition would have a great effect on its mechanical properties [19,22-24]. In addition, as a temperature-sensitive material, self-centering dampers with SMA 18 wires exhibited different mechanical properties at different temperatures [22], and the SMA wires also exhibited strong thermomechanical coupling while the state of the SMA wires was transformed from Austenite to Mantensite or Mantensite to Austenite [25]. However, it should be noted that the environmental temperatures of the self-centering dampers may have no obvious change in a room, and the heat absorption from Austenite to Mantensite is almost equal to the heat release from Mantensite to Austenite, so the effect of temperature on SMA wires will not be addressed in this paper, which should also be investigated in future research work.

This paper presents a comprehensive experimental investigation of the mechanical properties of $1.0 \mathrm{~mm}$ diameter SMA wires under different number of cycles, strain amplitudes, loading rates, and initial strains, which were pretreated by first tensioning to the 0.06 strain amplitude for 40 cycles; so, the hysteresis curves, energy dissipation capacity, transformation stress, and effective elastic modulus of the SMA wires will be investigated in detail. Then, an improved Graesser model program in the SIMULINK toolbox of MATLAB $2016 \mathrm{~b}$ is developed to simulate the hysteretic curves of the SMA wires, and the accuracy of the numerical results is verified by comparison to the test results. 


\section{SMA Wire Tests}

\subsection{Test Materials}

The $1.0 \mathrm{~mm}$ diameter SMA wires used in the test were manufactured by Gao'an Shape Memory Alloy Material Co., Ltd. (Yichun, Jiangxi, China). As reported from the manufacturer, the chemical composition of the SMA wires is shown in Table 1. The atomic mass ratios of the nickel element $(\mathrm{Ni})$ and titanium element $(\mathrm{Ti})$ of the SMA wires are $55.9600 \%$ and $43.9835 \%$, respectively. In addition, the mass density is $6350 \mathrm{~kg} / \mathrm{m}^{3}$, the upper plateau stress is $480 \mathrm{MPa}$, and the residual elongation of the SMA wires is $0.09 \%$. Based on the tested results from a differential scanning calorimeter (DSC), the Martensite start temperature, $M_{s}$, Martensite finish temperature, $M_{f}$, Austenite start temperature, $A_{s}$, and Austenite finish temperature, $A_{f}$, of the SMA wires are $28.9^{\circ} \mathrm{C}, 7.3{ }^{\circ} \mathrm{C}, 16.7^{\circ} \mathrm{C}$, and $35.2^{\circ} \mathrm{C}$, respectively.

Table 1. Composition of the shape memory alloy (SMA).

\begin{tabular}{cccccc}
\hline Element & Content $/ \%$ & Element & Content $/ \%$ & Element & Content $/ \%$ \\
\hline $\mathrm{Ni}$ & 55.9600 & $\mathrm{Ti}$ & 43.9835 & $\mathrm{H}$ & 0.0005 \\
$\mathrm{Cr}$ & 0.0070 & $\mathrm{Co}$ & 0.0030 & $\mathrm{C}$ & 0.0050 \\
$\mathrm{Fe}$ & 0.0060 & $\mathrm{Cu}$ & 0.0060 & Others & 0.0290 \\
\hline
\end{tabular}

\subsection{Test Setup}

The cyclic test of the SMA wires was carried out by a SANS electronic universal testing machine (EUTM) in Nanchang University Engineering Mechanics Experiment Center. The ends of the SMA wire, with the characteristics of having a small diameter and being smooth, should be firmly embedded within a special fixture. The test setup was composed of different parts, such as the sensor, upper fixture, lower fixture, long rod, and SMA wire, as shown in Figure 1. The upper fixture was connected to the sensor, and the lower fixture was coupled to the long rod. The initial gauge length of the SMA wire in the test setup was $375 \mathrm{~mm}$, which corresponds to the distance of the upper fixture and lower fixture. The cyclic displacement loading protocol described in Section 2.3 was performed to evaluate the mechanical properties of the SMA wire specimens, and the load and displacement of each specimen were recorded directly by the sensor in the EUTM. All the tests were conducted at room temperature (approximately $20-25{ }^{\circ} \mathrm{C}$ ), and the temperature was measured by a thermometer, which was fixed in the column of the EUTM.

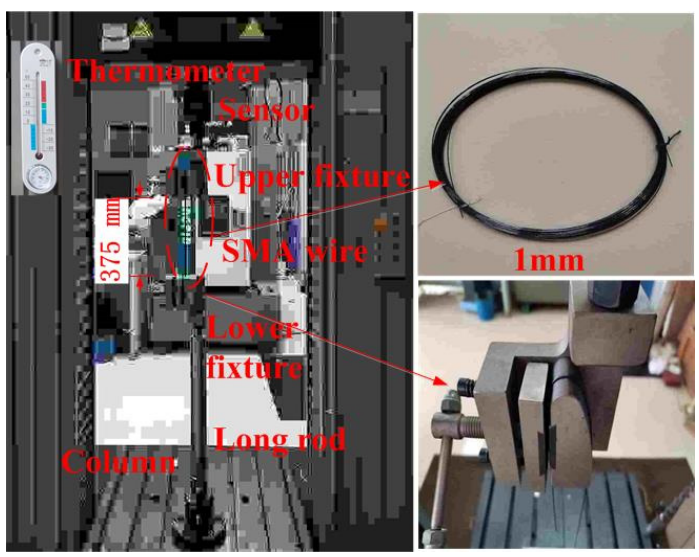

Figure 1. Test setup.

\subsection{Test Cases}

The cyclic loading-unloading test of eleven SMA wire specimens was performed to consider the effect of the number of cycles, loading rate, and pre-tension. For the pretreated cyclic loading, all the specimens were first tensioned to the 0.06 strain amplitude 24 for 
40 cycles. A single SMA wire specimen was subjected to each test case, and the test cases mainly include the following contents:

1. Number of cycles. Only one test case studied the effect of number of cycles, and the strain amplitude was 0.06 for 30 cycles, whereas the initial strain was zero at a $0.45 \mathrm{~mm} / \mathrm{s}$ loading rate and 0.0012/s strain rate, as in Qian [24].

2. Strain amplitude. One test case studied the effect of strain amplitude, and the strain amplitudes were $0.005,0.01,0.02,0.03,0.04,0.05$, and 0.06 , successively, whereas the loading rate was $0.45 \mathrm{~mm} / \mathrm{s}$, and the test was loaded for one cycle at a zero initial strain.

3. Loading rate. Five test cases studied the effect of loading rate; a total of five SMA wire specimens were set, which were $0.225 \mathrm{~mm} / \mathrm{s}, 0.450 \mathrm{~mm} / \mathrm{s}, 0.675 \mathrm{~mm} / \mathrm{s}, 0.900 \mathrm{~mm} / \mathrm{s}$, and $1.350 \mathrm{~mm} / \mathrm{s}$, respectively, whereas the strain amplitudes for each test case were $0.005,0.01,0.02,0.03,0.04,0.05$, and 0.06 , successively, and all the tests were loaded for one cycle at a zero initial strain.

4. Initial strain. Four test cases with four different initial strains studied the effect of the pre-tensioning, and the initial strains were set as $0.0025,0.0050,0.0075$, and 0.0100 , by applying a specified load, respectively, where the strain amplitudes for each test case were $0.005,0.01,0.02,0.03,0.04,0.05$, and 0.06 , successively, and all the tests were loaded for one cycle at a $0.45 \mathrm{~mm} / \mathrm{s}$ loading rate.

\section{Test Results}

Figure 2 shows the stress-strain curve of the SMA wires, and the six parameters of the key properties in a typical curve of the SMA wires are also illustrated in the Figure 2 [26]; i.e., the Austenite start transformation stress $\sigma_{f}^{A M}$, Austenite finish transformation stress $\sigma_{f}^{A M}$, the Martensite start transformation stress $\sigma_{s}^{M A}$, Martensite finish transformation stress $\sigma_{f}^{A M}$, maximum transformation strain $\overline{\varepsilon_{L}}$, and initial elastic modulus $E_{A}$. Based on the reasonable test materials, test setup, and test cases, the mechanical properties of the SMA wires considering the key factors will be accurately analyzed in detail. During the entire loading process, the SMA wires will be in a mixed state between Austenite and Martensite.

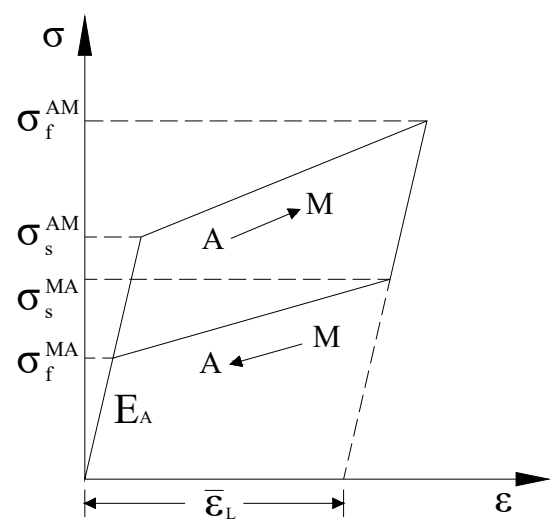

Figure 2. Stress-strain curve of the SMA wire [26].

\subsection{Effect of the Number of Cycles and Strain Amplitude}

Figure 3 shows the hysteresis curves, energy dissipation capacity, effective elastic modulus, and transformation stresses of the SMA wire at the different number of cycles $N$ and strain amplitude. It clearly shows the superelastic behavior with near-zero residual deformation at a maximum strain value of 0.06 , and the corresponding maximum stress is about $703 \mathrm{MPa}$. Figure 3a shows the hysteresis curves of the SMA wires at a 0.06 strain for 30 cycles and strain amplitude for one cycle, as shown in test cases (1) and (2) in Section 2.3, and the two curves are basically the same. The stress of the SMA wire will slightly decrease with the $N$ increasing, and a slight increment in stresses can be observed at the location near $\sigma_{s}^{M A}$ for one cycle. 


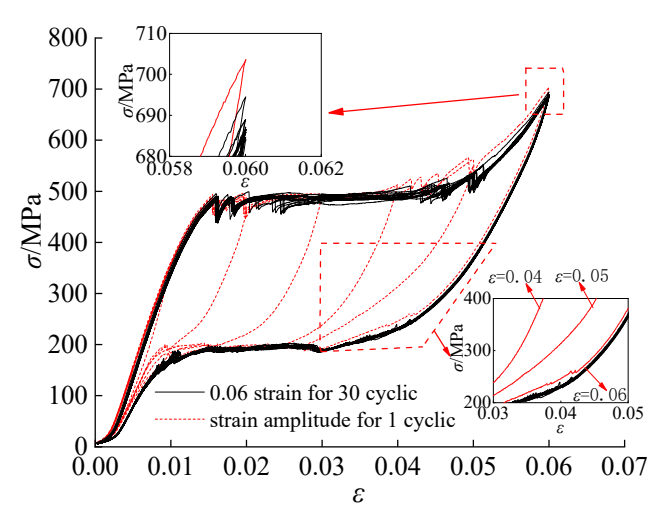

(a) Hysteresis curves

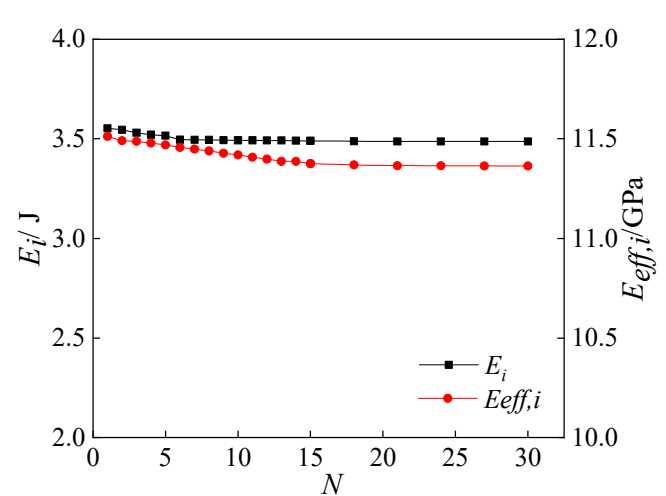

(b) Energy dissipation capacity and effective elastic modulus

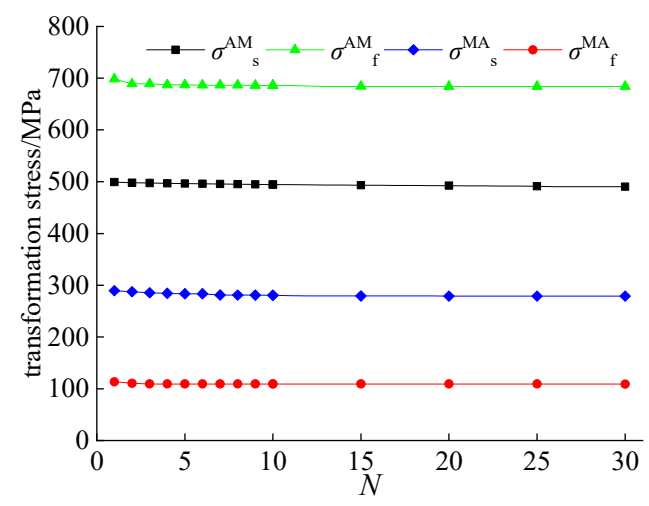

(c) Transformation stresses

Figure 3. Effect of the number of cycles and strain amplitude on the mechanical properties of SMA wire.

The effective elastic modulus, $E_{e f f, i}$, is an important parameter to evaluate the mechanical property of SMA wire, which can be defined as the diagonal modulus of the $i$ th cycle loading loop in Equation (1):

$$
E_{e f f, i}=\frac{\sigma_{\max , i}-\sigma_{\min , i}}{\varepsilon_{\max , i}-\varepsilon_{\max , i}}
$$

in which $\sigma_{\max , i}$ and $\sigma_{\min , i}$ are the maximum and minimum stress value of the $i$ th cycle loading, in which $\varepsilon_{\max , i}$ and $\varepsilon_{\min , i}$ are the maximum and minimum strain value of the $i$ th cycle loading.

Figure $3 b$ shows the energy dissipation value and effective elastic modulus of SMA wires under 30 loading cycles. The energy dissipation value, $E_{i}$, can be observed to slightly decrease from $3.55 \mathrm{~J}$ to $3.50 \mathrm{~J}$ as the number of cycles $N$ increases from 1 to 5; then, the $E_{i}$ gradually becomes stable with no obvious change as the number of cycles increases. In addition, the effective elastic modulus, $E_{\text {eff, } i}$, will decrease from $11.51 \mathrm{GPa}$ to $11.38 \mathrm{GPa}$ as the $N$ increases to 15 , and the $E_{\mathrm{eff}, i}$ is almost constant when the $N$ ranges from 16 to 30 . Figure $3 c$ shows the four transformation stresses illustrated in Figure 2, and the effects of the number of cycles are also manifested. A slight decrement in the four transformation stresses can be found for cycles 1 to 5 , and as the number of cycles increases, all the transformation stresses become stable.

From the above test results, it can be confirmed that the number of cycles is one of the factors for the hysteresis curve, energy dissipation capacity, effective elastic modulus, and transformation stresses of SMA wires, but the influence is less clear, which is same with the existing results obtained from Lin [19], Desroches [23], and Wang [27]. Therefore, only one cycle with strain amplitude will be used to analyze the effect of the loading rate and initial strain on the SMA wire. 


\subsection{Effect of Loading Rates}

The hysteresis curves in Figure 4a are obtained from test case (3) in Section 2.3, with five different loading rates, which have the same trend and preferable energy dissipation capacity. As the loading rate increases, it can be seen that the maximum stress is gradually increased, which are $690 \mathrm{MPa}, 703 \mathrm{MPa}, 712 \mathrm{MPa}, 721 \mathrm{MPa}$, and $731 \mathrm{MPa}$ at the loading rates of $0.225 \mathrm{~mm} / \mathrm{s}, 0.450 \mathrm{~mm} / \mathrm{s}, 0.675 \mathrm{~mm} / \mathrm{s}, 0.900 \mathrm{~mm} / \mathrm{s}$, and $1.350 \mathrm{~mm} / \mathrm{s}$, respectively. However, the stresses at the unloading process after the ultimate strain amplitude will also slightly increase with the loading rate increasing, which indicates the pinch phenomenon of the hysteresis curves; the energy dissipation value $E_{i}$ need to be further analyzed.

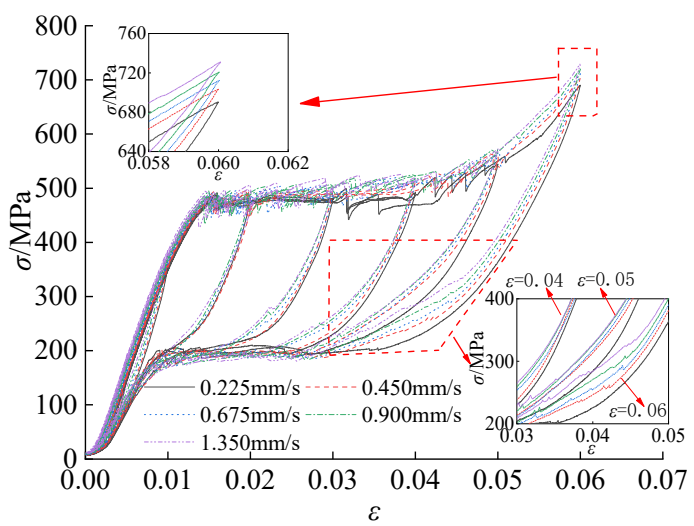

(a) Hysteresis performance

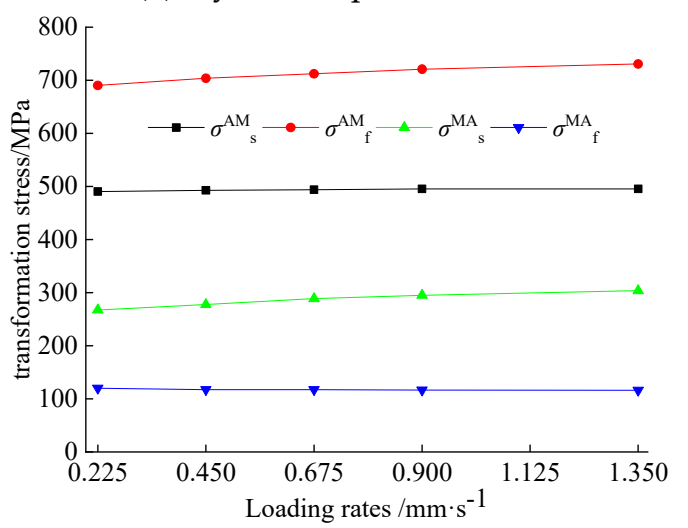

(c) Transformation stresses

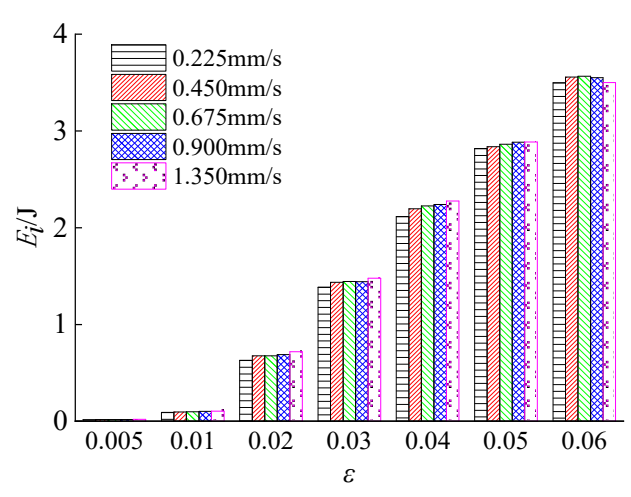

(b) Energy dissipation capacity

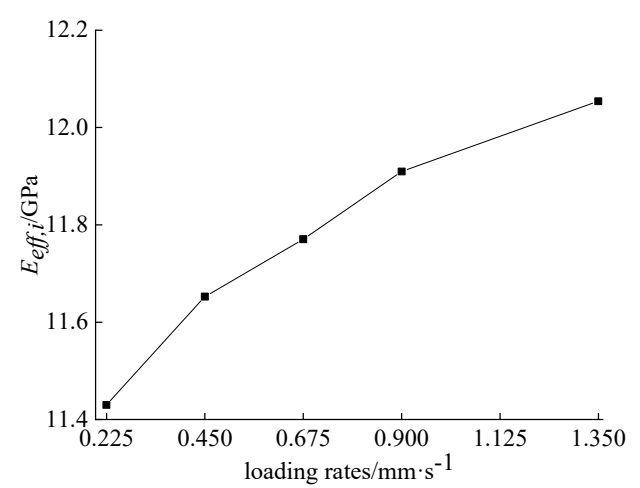

(d) Effective elastic modulus

Figure 4. Effect of loading rate on the mechanical properties of the SMA wire.

Figure $4 \mathrm{~b}$ shows the energy dissipation of the SMA wires with different loading rates, and the $E_{i}$ is the enclosed area of each of the loading-unloading curves. An increment in $E_{i}$ for the specimens with the increase in loading rate can be seen when the strain amplitude is increased from 0.005 to 0.05 ; this is mainly due to the increment of the enclosed area at the ultimate strain amplitude being larger than the pinch phenomenon of the hysteresis curve. However, an increment of $E_{i}$ at 0.06 strain can be observed when the loading rate is increased from $0.225 \mathrm{~mm} / \mathrm{s}$ to $0.675 \mathrm{~mm} / \mathrm{s}$; then, a gradual decrease will occur as the loading rate increases to $1.350 \mathrm{~mm} / \mathrm{s}$, so the effect of the pinch phenomenon is surely enlarged.

Figure $4 \mathrm{c}$ shows the transformation stresses of the SMA wires with different loading rates. As the loading rate increases from $0.225 \mathrm{~mm} / \mathrm{s}$ to $1.350 \mathrm{~mm} / \mathrm{s}$, the $\sigma_{s}^{A M}$ slightly increases from $490 \mathrm{MPa}$ to $495 \mathrm{MPa}, \sigma_{f}^{A M}$ increases from $690 \mathrm{MPa}$ to $731 \mathrm{MPa}, \sigma_{s}^{M A}$ increases from $259 \mathrm{MPa}$ to $306 \mathrm{MPa}$, and that of $\sigma_{f}^{M A}$ correspondingly decrease from $119 \mathrm{MPa}$ to $116 \mathrm{MPa}$. The transformation stresses results also demonstrate the pinch phenomenon 
of the hysteresis curves for loading rates. Figure $4 \mathrm{~d}$ shows the effective elastic modulus $E_{\mathrm{eff}, i}$ of the SMA wires with different loading rates, and the results indicate that the $E_{\mathrm{eff}, i}$ at loading rates of $0.225 \mathrm{~mm} / \mathrm{s}, 0.450 \mathrm{~mm} / \mathrm{s}, 0.675 \mathrm{~mm} / \mathrm{s}, 0.900 \mathrm{~mm} / \mathrm{s}$, and $1.350 \mathrm{~mm} / \mathrm{s}$ is 11.43 GPa, 11.65 GPa, 11.77 GPa, $11.91 \mathrm{GPa}$, and 12.05 GPa, respectively. The $E_{\text {eff }, i}$ increases with increasing the loading rates, which is mainly caused by the change in $\sigma_{f}^{A M}$ and $\sigma_{f}^{M A}$.

Based on the above discussion, it can be concluded that the loading rate is also one of the factors affecting the mechanical properties of SMA wires. In addition, the energy dissipation capacity and corresponding mechanical properties of the SMA wire are best when the loading rate is $0.675 \mathrm{~mm} / \mathrm{s}$.

\subsection{Effect of Initial Strain}

By means of test case (4) in Section 2.3, the hysteresis curves of the pre-tensioned SMA wires with different initial strains $\Delta \varepsilon$ are shown in Figure 5, which also have the same trend and a good energy dissipation capacity with non-residual deformation. The maximum stresses of the SMA wires are $742 \mathrm{MPa}, 776 \mathrm{MPa}, 807 \mathrm{MPa}$, and $813 \mathrm{MPa}$ at the initial strains of $0.0025,0.0050,0.0075$, and 0.0100 , respectively, which significantly increase with the $\Delta \varepsilon$ increasing. In addition, the Martensite finish transformation stress $\sigma_{f}^{M A}$ is found to be significantly increased with increasing the $\Delta \varepsilon$; meanwhile, the stress-strain curve between $\sigma_{s}^{A M}$ and $\sigma_{f}^{M A}$ becomes less steep, and the hysteresis area decreases progressively and little energy is dissipated at locations near $\sigma_{f}^{M A}$.

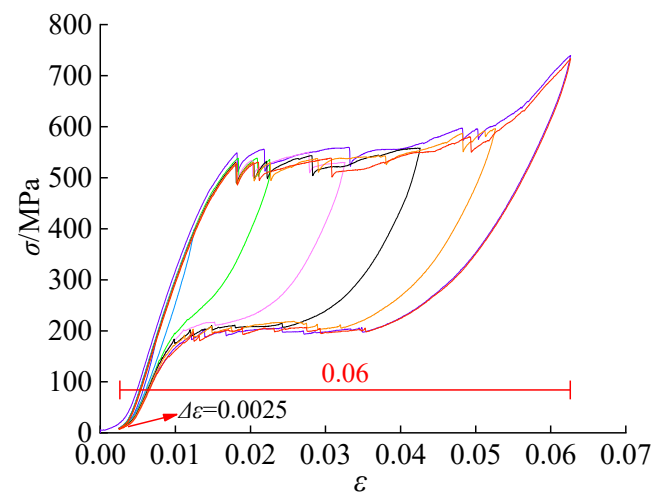

(a) $\Delta \varepsilon=0.0025$

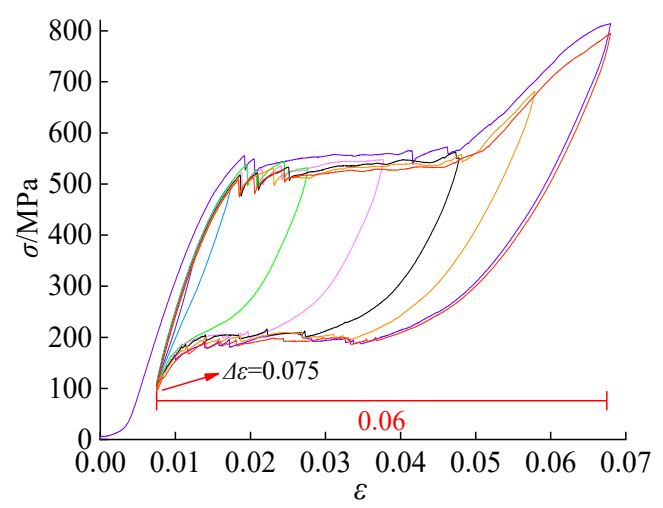

(c) $\Delta \varepsilon=0.0075$

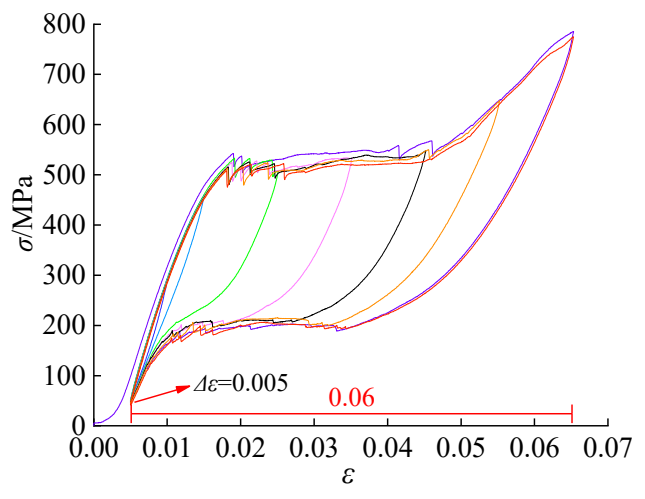

(b) $\Delta \varepsilon=0.0050$

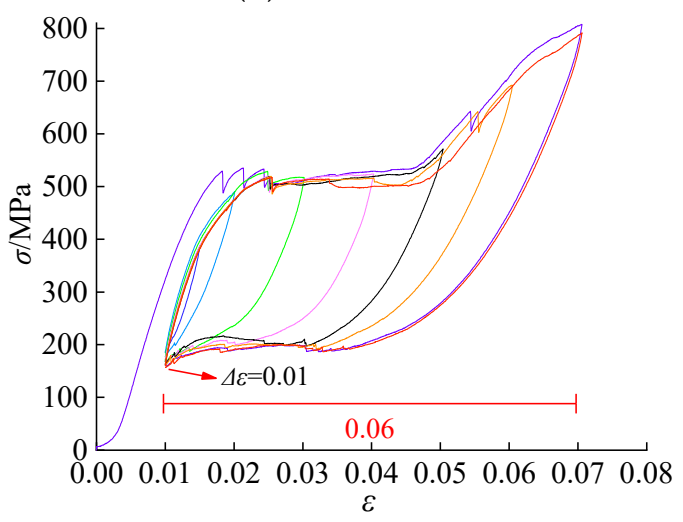

(d) $\Delta \varepsilon=0.0100$

Figure 5. Effect of the initial strain on the hysteresis curve of the pre-tensioned SMA wire.

The different energy dissipations of the pre-tensioned SMA wires is shown in Figure 6a. An increment of $E_{i}$ for the SMA wires with an increase in $\Delta \varepsilon$ from 0.0025 to 0.0075 can be obviously observed under different strain amplitudes, which has mainly been caused by the increment of the hysteresis areas. Then, the energy dissipation capability for a 0.0075 initial strain is stronger than that of a 0.0100 initial strain; it can be concluded 
that the increment of hysteresis area at the 0.06 strain is smaller than the decrement of the hysteresis area at the locations near $\sigma_{f}^{M A}$. Figure $6 \mathrm{~b}$ shows the transformation stresses of the SMA wires with different $\Delta \varepsilon$. As the $\Delta \varepsilon$ increases from 0.0025 to 0.0100 , with the $\sigma_{s}^{A M}$ significantly decreasing from $488 \mathrm{MPa}$ to $434 \mathrm{MPa}, \sigma_{f}^{A M}$ significantly increases from $742 \mathrm{MPa}$ to $813 \mathrm{MPa}, \sigma_{s}^{M A}$ decreases from $288 \mathrm{MPa}$ to $259 \mathrm{MPa}$, and that of $\sigma_{f}^{M A}$ increases from $119 \mathrm{MPa}$ to $157 \mathrm{MPa}$. The transformation stress results indicate that the slope of the stress-strain curve between $\sigma_{s}^{M A}$ and $\sigma_{f}^{A M}$ gradually increases while the slope of the stress-strain curve between $\sigma_{s}^{M A}$ and $\sigma_{f}^{M A}$ decreases. Figure $6 \mathrm{c}$ shows the $E_{\mathrm{eff}, i}$ of the SMA wires with different $\Delta \varepsilon$, and the $E_{\mathrm{eff}, i}$ at $\Delta \varepsilon$ of $0.0025,0.0050,0.0075$, and 0.0100 is $12.21 \mathrm{GPa}$, 12.15 GPa, 11.73 GPa, and 10.77 GPa, respectively. The $E_{\text {eff }, i}$ decreases with increasing the $\Delta \varepsilon$ due to the increased difference between $\sigma_{f}^{A M}$ and $\sigma_{f}^{M A}$.

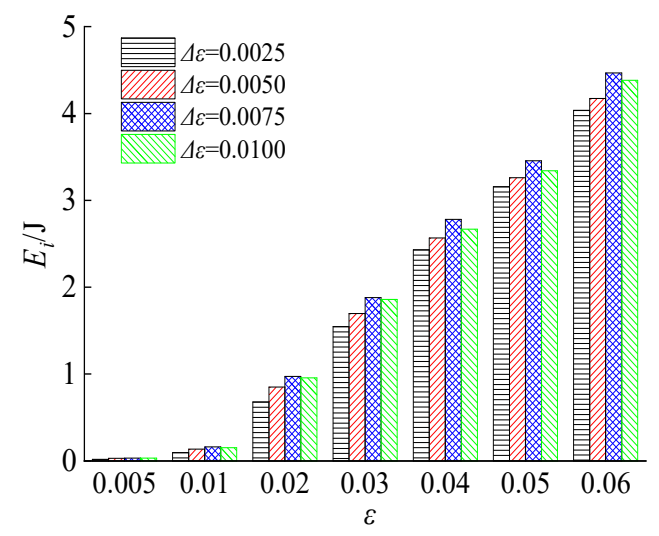

(a) Energy dissipation capacity

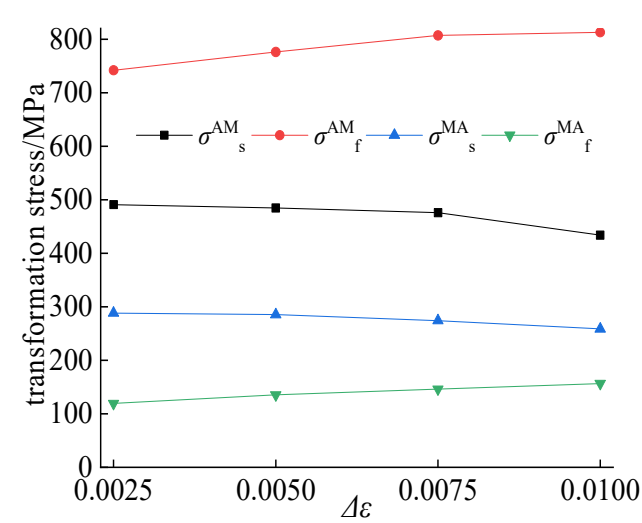

(b) Transformation stresses

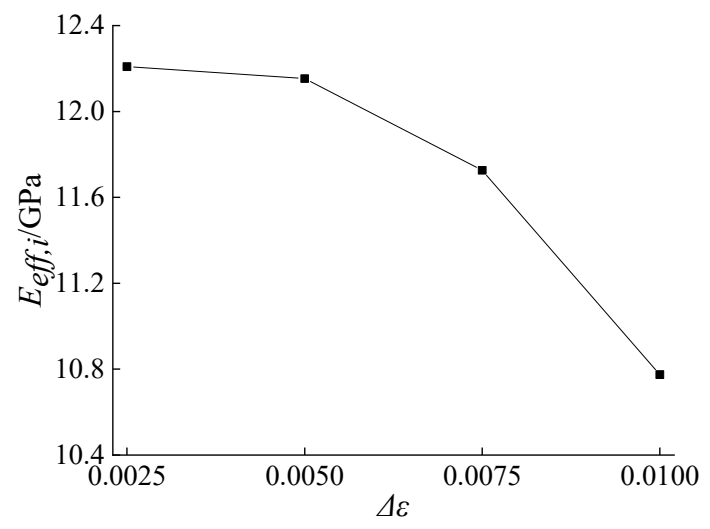

(c) Effective elastic modulus

Figure 6. Effect of the mechanical property of the pre-tensioned SMA wire.

Based on the above description, it can be seen that the $\Delta \varepsilon$ is also one of the main factors for determining the mechanical properties of SMA wires, and the energy dissipation capacity of the SMA wire is best when the $\Delta \varepsilon$ is 0.0075 .

\section{Numerical Results}

A numerical analysis using the improved Graesser model was conducted to investigate the mechanical properties of an SMA wire based on the SIMULINK toolbox of MATLAB, and the numerical results were compared to those of the test results.

\subsection{Numerical Model of the SMA Wire}

The force of the SMA wire can be expressed by Equation (2):

$$
F_{S M A}=\sigma_{S M A} A_{S}
$$


where $A_{S}$ is the cross-sectional area of the SMA wire, and $\sigma_{S M A}$ is the stress of the SMA wire. Based on the Graesser model [28], the time derivative of $\sigma_{S M A}, \dot{\sigma}$, can be described by Equation (3):

$$
\sigma=E\left[\dot{\varepsilon}-|\dot{\varepsilon}|\left(\frac{\sigma-\beta}{Y}\right)^{n}\right]
$$

where $\dot{\varepsilon}$ is the time derivative of $\varepsilon, \varepsilon$ is equal to $\Delta L / L, \Delta L$ is the relative displacement, and $L$ is the initial length of the SMA wire; $E$ is the elastic modulus and $Y$ is the yield stress of the SMA wire; $n$ is a constant controlling the sharpness of the transition from the elastic\&\#13; state to phase transformation; and $\beta$ is the one dimensional back stress and can be expressed by Equation (4):

$$
\beta=E \alpha\left\{\varepsilon_{i n}-\frac{\sigma}{E}+f_{T}|\varepsilon|^{c} \operatorname{erf}(a \varepsilon)[u(-\varepsilon \dot{\varepsilon})]\right\}
$$

where $\alpha$ is equal to $E_{y} /\left(E-E_{y}\right)$, and $E_{y}$ is the slope of the stress-strain curve after the elastic range; $\varepsilon_{i n}$ is the inelastic strain, which is equal to $\varepsilon_{i n}=\varepsilon-\sigma / E ; f_{T}$ is the material constant controlling the type and size of the hysteresis; $a$ is the constant controlling the amount of elastic recovery; and $c$ is the constant controlling the slop of the unloading stress plateau. In addition, $\operatorname{erf}(x)$ is the error function, and $u(x)$ is the Heaviside function, which can be expressed by Equation (5) and (6):

$$
\begin{gathered}
\operatorname{erf}(x)=\frac{2}{\sqrt{x}} \int_{0}^{x} e^{-t^{2}} d t \\
u(x)= \begin{cases}1 & (x \geq 0) \\
0 & (x<0)\end{cases}
\end{gathered}
$$

An improved Graesser model, considering the mechanical behavior under large deformation, was proposed by Qian [24], which can be expressed by Equations (7) and (8):

$$
\begin{array}{r}
\sigma=E\left[\dot{\varepsilon}-|\dot{\varepsilon}|\left(\frac{\sigma-\beta}{Y}\right)^{n-1}\left(\frac{\sigma-\beta}{Y}\right)\right] \\
\beta=E \alpha\left\{\varepsilon_{i n}-\frac{\sigma}{E}+f_{T}|\varepsilon|^{c} \operatorname{erf}(a \varepsilon)[u(-\varepsilon \dot{\varepsilon})]+f_{M}\left[\varepsilon-\varepsilon_{M_{f}} \operatorname{sgn}(\varepsilon)\right]^{m}[u(\varepsilon \dot{\varepsilon})]\left[u\left(|\varepsilon|-\varepsilon_{M_{f}}\right)\right]\right\}
\end{array}
$$

where $\varepsilon_{M f}$ is the Martensite finish transformation strain; and $f_{M}$ and $m$ are the constants controlling the Martensite hardening curve. $\operatorname{sgn}(x)$ is the symbolic function, which is expressed by Equation (9):

$$
\operatorname{sgn}(x)= \begin{cases}+1 & x>0 \\ 0 & x=0 \\ -1 & x<0\end{cases}
$$

By combing Equations (7) and (8), the stress-strain relation of the SMA wires will be revealed in detail using the numerical analysis.

\subsection{Comparison of the Test and Numerical Results}

Based on the SMA wire testing results in Section 3, the numerical model factors mentioned in Section 4.2.1 for SMA wire with different influencing factors can be determined; $c=0.001, n=3$, and $m=3$, with the other model parameters listed in Table 2 . 
Table 2. The parameters for each mechanical model.

\begin{tabular}{ccccccccc}
\hline Influencing Factor & Value & $E$ & $\boldsymbol{Y}$ & $\boldsymbol{\alpha}$ & $f_{\mathrm{T}}$ & $\boldsymbol{a}$ & $\varepsilon_{M f}$ & $f_{\mathrm{M}}$ \\
\hline Strain amplitude & $0.005-0.06$ & 45,000 & 480 & 0.0190 & 0.77 & 250 & 0.040 & 42,500 \\
\hline & 0.225 & 45,000 & 470 & 0.0190 & 0.78 & 280 & 0.040 & 42,500 \\
& 0.450 & 47,000 & 480 & 0.0190 & 0.74 & 275 & 0.040 & 42,500 \\
Loading rate/mm/s & 0.675 & 49,000 & 500 & 0.0190 & 0.71 & 270 & 0.040 & 42,500 \\
& 0.900 & 50,000 & 500 & 0.0200 & 0.67 & 265 & 0.040 & 42,500 \\
& 1.350 & 51,000 & 500 & 0.0210 & 0.63 & 255 & 0.040 & 42,500 \\
\hline \multirow{3}{*}{ Pre-tensioned } & 0.0025 & 50,000 & 530 & 0.0200 & 0.70 & 282 & 0.040 & 42,500 \\
& 0.0050 & 51,000 & 520 & 0.0190 & 0.72 & 290 & 0.040 & 42,500 \\
& 0.0075 & 52,000 & 508 & 0.0164 & 0.08 & 300 & 0.036 & 33,500 \\
& 0.0100 & 53,000 & 500 & 0.0150 & 0.87 & 310 & 0.036 & 33,300 \\
\hline
\end{tabular}

\subsubsection{Strain Amplitude}

The improved Graesser model programs in the SIMULINK toolbox of MATLAB were developed to simulate the hysteretic curve of the SMA wires, and Figure 7 displays the comparisons between the test results in Figure $3 a$ and numerical results under strain amplitude for one cycle. A significant difference in hysteretic curves between the test and numerical results is found at the 0.005 strain, which may be explained by the existence of a minute initial strain of the SMA wire in the test result. Then, the comparison of both results is made for the strain from 0.01 to 0.04 , and it shows good agreement. When the strain reaches 0.05 and 0.06 , the maximum stresses of the SMA wire for both results are very close, but little difference in stresses between the test and numerical results for the 0.05 and 0.06 strains are found at the location near $\sigma_{s}^{M A}$.

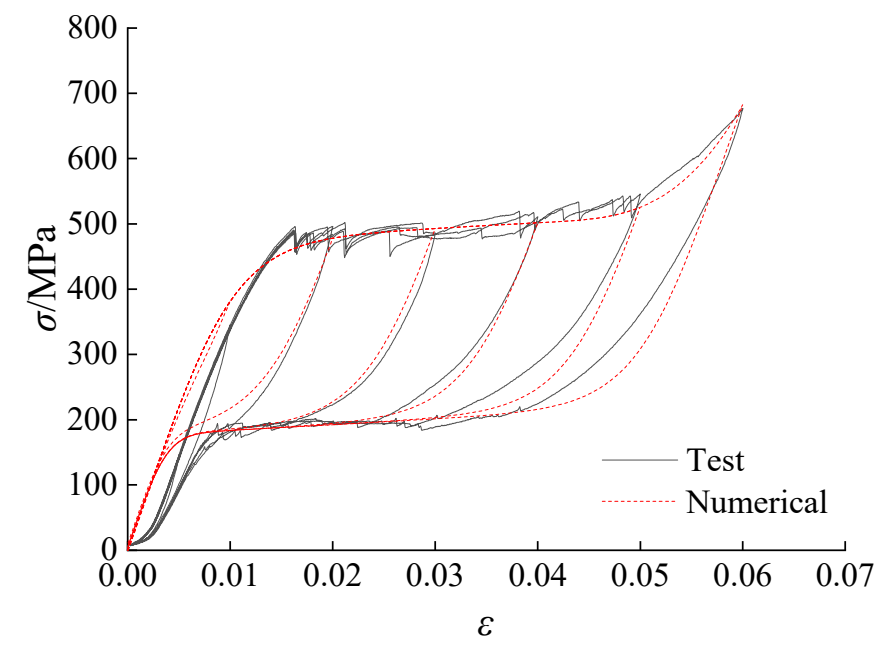

Figure 7. Comparison of the test and numerical curves under strain amplitude.

The errors of $\Delta_{i E}$ and $\Delta_{i F}$ between the experimental and numerical values of energy dissipation value $E_{i}$ and ultimate force $F_{i}$ can be expressed by Equation (10):

$$
\left\{\begin{aligned}
\Delta_{i E} & =\left(E_{i T}-E_{i N}\right) / E_{i T} \\
\Delta_{i F} & =\left(F_{i T}-F_{i N}\right) / F_{i T}
\end{aligned}\right.
$$

where $E_{i T}$ and $E_{i N}$ are the experimental and numerical energy dissipation value, respectively; $F_{i T}$ and $F_{i N}$ are the experimental and numerical ultimate force, respectively.

The energy dissipation value $E_{i}$ and ultimate force $F_{i}$ were then calculated from the hysteresis curves to further validate the effectiveness of the presented numerical analysis method, as given in Table 3. The maximum errors of the $E_{i}$ and $F_{i}$ are $39.73 \%$ and $-12.10 \%$ 
at a strain of 0.005 , respectively, and the reason has been explained in the difference between the hysteresis curves. As the strain increases from 0.01 to 0.06 , the maximum errors of $E_{i}$ and $F_{i}$ between the test and numerical results are $-8.65 \%$ and $5.26 \%$, respectively, from which it can be confirmed that both indices are very close, so the presented numerical model can be used to simulate the hysteresis curves of the SMA wires under strain amplitudes.

Table 3. Comparison of results under the strain amplitude.

\begin{tabular}{ccccccc}
\hline \multirow{2}{*}{ Step/N } & \multicolumn{3}{c}{ Energy Dissipation Value $E_{i} /(\mathrm{J})$} & \multicolumn{3}{c}{ Ultimate Force $F_{\boldsymbol{i}} /(\mathrm{N})$} \\
\cline { 2 - 7 } & Test & Numerical & $\boldsymbol{\Delta}_{\boldsymbol{i} \text { E }} / \%$ & Test & Numerical & $\boldsymbol{\Delta}_{\boldsymbol{i} \boldsymbol{F}} / \%$ \\
\hline 1 & 0.017 & 0.010 & 39.73 & 327.23 & 366.82 & -12.10 \\
2 & 0.097 & 0.089 & 7.69 & 362.55 & 381.64 & -5.26 \\
3 & 0.68 & 0.64 & 4.77 & 462.36 & 478.06 & -3.39 \\
4 & 1.43 & 1.39 & 3.43 & 495.45 & 492.88 & 0.52 \\
5 & 2.20 & 2.24 & -2.24 & 513.20 & 501.66 & 2.25 \\
6 & 2.84 & 3.08 & -8.65 & 549.94 & 525.58 & 4.43 \\
7 & 3.56 & 3.77 & -6.04 & 703.70 & 682.69 & 2.98 \\
\hline
\end{tabular}

\subsubsection{Loading Rate}

Figure 8a-e show the comparisons between the test results in Figure 4a and numerical results under different loading rates, and in order to improve the calculation efficiency, all the loading strains can only be set as 0.06 due to the accuracy of the strain amplitude for Steps 1-7 in Table 3. As the loading rate increases from $0.225 \mathrm{~mm} / \mathrm{s}$ to $1.350 \mathrm{~mm} / \mathrm{s}$, the hysteresis curves obtained by the test results all show close agreement with the numerical predictions. However, the minute initial strain of the SMA wires also influences the test curve at the beginning of loading, and the difference in stress between the test and numerical results increases with the increasing of the loading rate at the location near $\sigma_{s}^{M A}$.

For the different loading rates, the $E_{i}$ and $F_{i}$ of the SMA wires calculated from test and numerical analysis are shown in Table 4 . As the loading rate increases from $0.225 \mathrm{~mm} / \mathrm{s}$ to $1.350 \mathrm{~mm} / \mathrm{s}$, the error of $E_{i}$ between the test and numerical results gradually increases, and the maximum value is $-13.69 \%$. The major reason for the error may due to the difference in stress at the location near $\sigma_{s}^{M A}$. Meanwhile, the maximum error $F_{i}$ for the different loading rates is only $0.48 \%$, which has good accuracy. Therefore, the presented numerical model can also be used to simulate the mechanical performance of the SMA wires under different loading rates.

Table 4. Comparison of results under different loading rates.

\begin{tabular}{|c|c|c|c|c|c|c|}
\hline \multirow{2}{*}{$\begin{array}{c}\text { Loading } \\
\text { Rate } /\left(\mathrm{mm} \cdot \mathbf{s}^{-1}\right)\end{array}$} & \multicolumn{3}{|c|}{ Energy Dissipation Value $E_{i} /(\mathrm{J})$} & \multicolumn{3}{|c|}{ Ultimate Force $F_{i} /(\mathrm{N})$} \\
\hline & Test & Numerical & $\Delta_{i E} / \%$ & Test & Numerical & $\Delta_{i F} / \%$ \\
\hline 0.225 & 3.50 & 3.70 & -5.72 & 685.90 & 693.53 & -0.48 \\
\hline 0.450 & 3.56 & 3.81 & -7.04 & 690.19 & 701.73 & 0.28 \\
\hline 0.675 & 3.57 & 4.04 & -13.25 & 703.70 & 712.10 & 0.02 \\
\hline 0.900 & 3.54 & 4.01 & -13.38 & 712.23 & 718.97 & 0.26 \\
\hline 1.350 & 3.50 & 3.98 & -13.69 & 720.81 & 727.98 & 0.44 \\
\hline
\end{tabular}




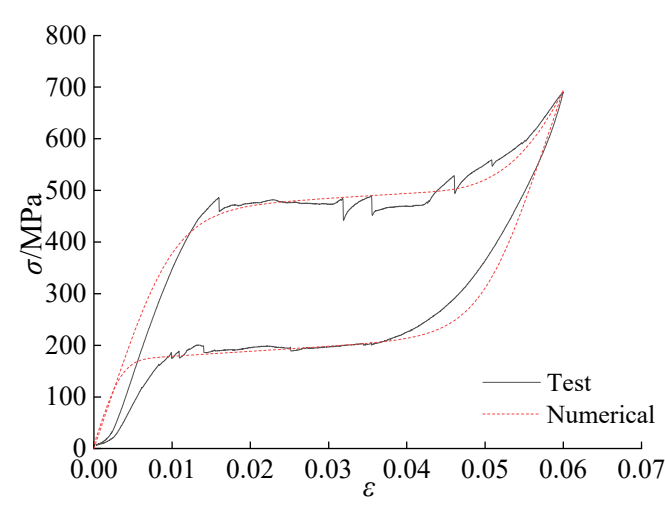

(a) Loading rate at $0.225 \mathrm{~mm} / \mathrm{s}$

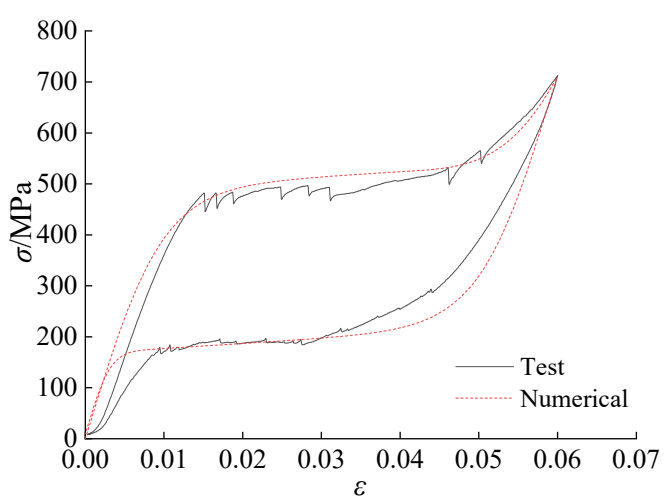

(c) Loading rate at $0.675 \mathrm{~mm} / \mathrm{s}$

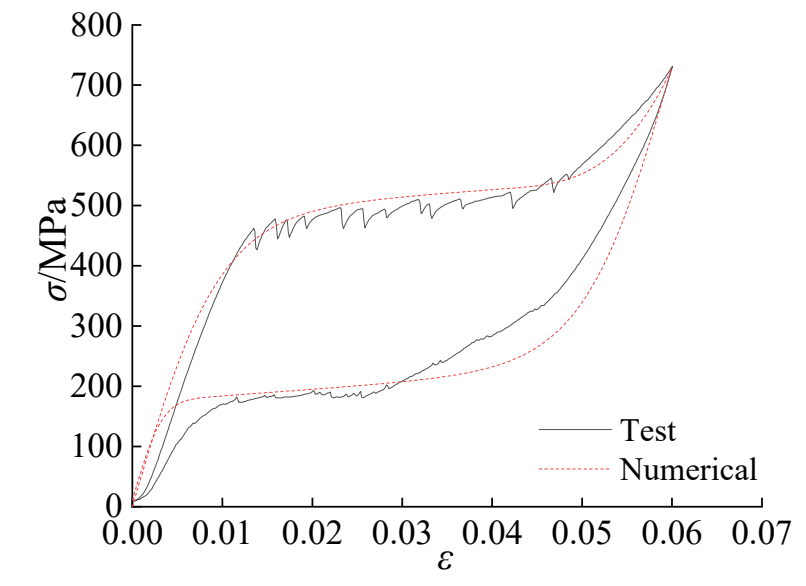

(e) Loading rate at $1.350 \mathrm{~mm} / \mathrm{s}$

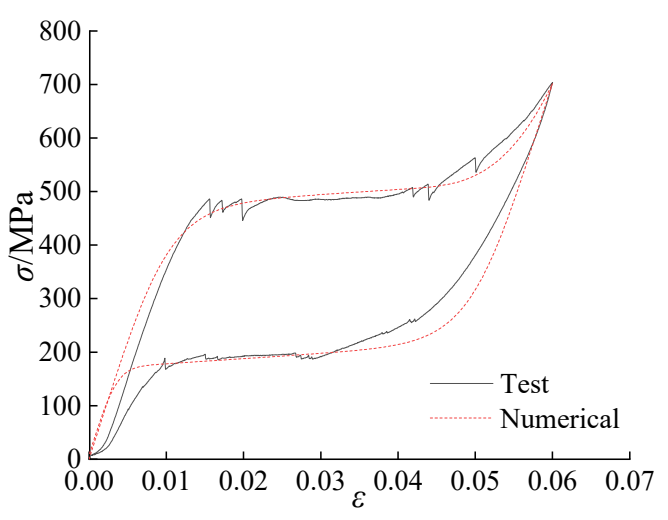

(b) Loading rate at $0.450 \mathrm{~mm} / \mathrm{s}$

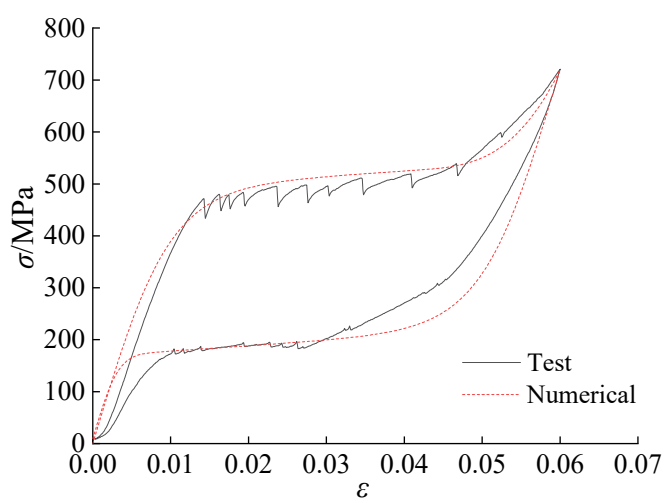

(d) Loading rate at $0.900 \mathrm{~mm} / \mathrm{s}$

Figure 8. Comparison of the test and numerical curves under different loading rates.

\subsubsection{Initial Strain}

Figure 9a-d show the comparisons between the test and numerical results under different initial strains of the pre-tensioned SMA wire at the 0.06 strain. The hysteresis curve at 0.0025 initial strain obtained by the test result is consistent with that of the numerical curve. As the initial strain continues to increase from 0.0050 to 0.0100 , the numerical results agree well with the test date, but there are two differences in the location near $\sigma_{s}^{M A}$ and $\sigma_{f}^{A M}$, which increases with the increasing of the initial strain. In addition, owing to the pre-strain applied before loading, no relaxation phenomenon and residual deformation are found in all the results. 


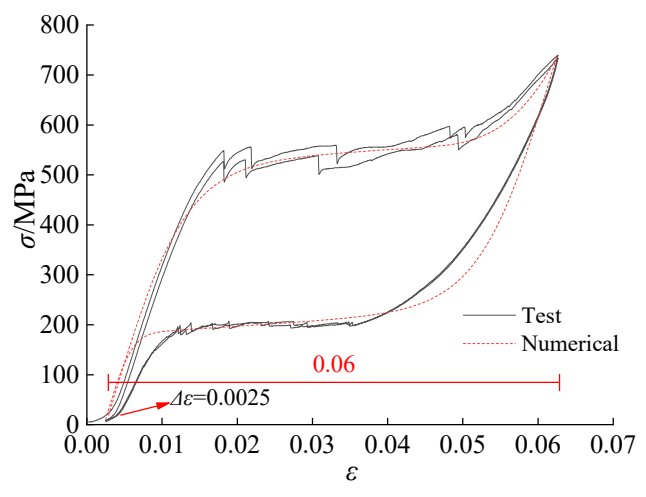

(a) Initial strain at 0.0025

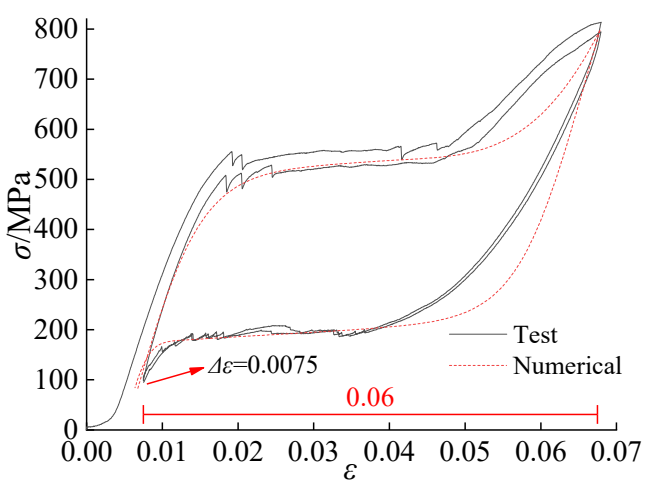

(c) Initial strain at 0.0075

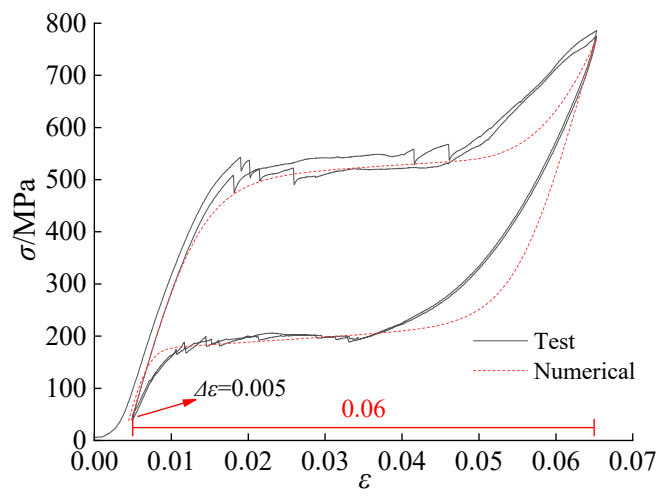

(b) Initial strain at 0.0050

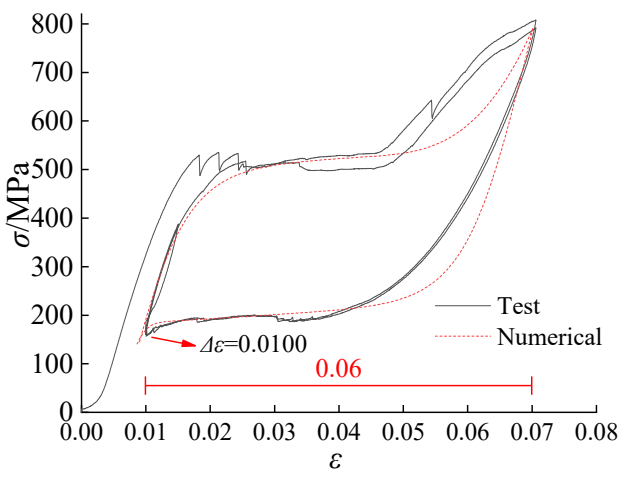

(d) Initial strain at 0.0100

Figure 9. Comparison of test and numerical curves under different initial strain for the pre-tensioned SMA wire.

For the different initial strains, the $E_{i}$ and $F_{i}$ of the pre-tensioned SMA wires obtained from test and numerical analysis are shown in Table 5. As the initial strain increases from 0.0025 to 0.0100 , the maximum error of $E_{i}$ between the test and numerical is only $-3.03 \%$, and the hysteresis area increasing at the location near $\sigma_{S}^{M A}$ is almost the same as the hysteresis area decreasing at the location near $\sigma_{f}^{A M}$ for all the pre-tensioned SMA wires. The maximum error $E_{i}$ for the different initial strains is only $1.29 \%$, which also has good agreement. However, investigations are still needed to modify the improved Graesser model of a pre-tensioned SMA wire under large deformation.

Table 5. Comparison of the results under different pre-tensions.

\begin{tabular}{|c|c|c|c|c|c|c|}
\hline \multirow{2}{*}{ Pre-Tension } & \multicolumn{3}{|c|}{ Energy Dissipation Value $E_{i} /(\mathrm{J})$} & \multicolumn{3}{|c|}{ Ultimate Force $F_{i} /(\mathrm{N})$} \\
\hline & Test & Numerical & $\Delta_{i E} / \%$ & Test & Numerical & $\Delta_{i F} / \%$ \\
\hline 0.0025 & 4.04 & 4.19 & -3.80 & 742.09 & 736.78 & 0.72 \\
\hline 0.0050 & 4.17 & 4.23 & -1.41 & 776.71 & 772.45 & 0.55 \\
\hline 0.0075 & 4.47 & 4.60 & -3.03 & 806.93 & 799.51 & 0.92 \\
\hline 0.0100 & 4.38 & 4.37 & 0.33 & 812.87 & 802.39 & 1.29 \\
\hline
\end{tabular}

\section{Conclusions}

The mechanical properties of the pretreated SMA wires with a different number of cycles, strain amplitudes, loading rates, and initial strains are investigated in this study, and the hysteresis curves, energy dissipation capacity, effective elastic modulus, and transformation stresses of the SMA wires with a consideration of many influencing factors are evaluated by experimental and numerical analysis. The following conclusions can be drawn from this study: 
1. Number of cycles and strain amplitude. The mechanical properties of the SMA wires obtained by only one loading cycle with strain amplitude shows great agreement with that of 30 loading cycles at 0.06 strain, which exhibits a stable performance.

2. Loading rate. The pinch effect of the hysteresis curves of the SMA wires will be enlarged with the increasing loading rates; meanwhile, the $E_{\text {eff }, i}$ and slope of transformation stresses are also increased during the cyclic tensile test. The maximum $E_{i}$ of the SMA wires appears at a loading rate of $0.675 \mathrm{~mm} / \mathrm{s}$.

3. Initial strain. As the initial strain increases, the slope of the transformation curve between $\sigma_{s}^{A M}$ and $\sigma_{f}^{A M}$ gradually increases, while the $E_{\mathrm{eff}, i}$ and slope of the transformation curve between $\sigma_{s}^{M A}$ and $\sigma_{f}^{M A}$ decreases. The maximum $E_{i}$ of the pre-tensioned SMA wires appears on the initial strain of 0.0075 .

4. The improved Graesser model programs in the SIMULINK toolbox of MATLAB can be used to simulate the mechanical property of the SMA wires with a different number of cycles, strain amplitudes, loading rates, and initial strains, but it also needs to study the improved numerical model of the pre-tensioned SMA wire under large deformation in the future.

Author Contributions: Conceptualization, S.H., Y.J.; methodology, B.Z., S.H.; software, F.T., Q.Z.; validation, F.T., S.H.; formal analysis, B.Z., S.Z., F.T., S.H., Q.Z., Y.J.; writing-original draft preparation, B.Z., S.Z., F.T.; writing-review and editing, S.H., Q.Z., Y.J.; supervision, S.H., Y.J.; project administration, S.H., Y.J.; funding acquisition, S.H. All authors have read and agreed to the published version of the manuscript.

Funding: The authors gratefully acknowledge the research grant provided by the National Nature Science Foundation of China (No. 51768044, 51908268, 51968047), Jiangxi Postdoctoral Science Foundation (2019KY57).

Institutional Review Board Statement: Not applicable.

Informed Consent Statement: Not applicable.

Data Availability Statement: The data used to support the findings of this study are available from the corresponding author upon request.

Conflicts of Interest: The authors confirm that this article content has no conflict of interest.

\section{References}

1. Costanza, G.; Paoloni, S.; Tata, M.E. Ir thermography and resistivity investigations on Ni-Ti shape memory alloy. Key Eng. Mat. 2014, 605, 23-26. [CrossRef]

2. Mohd, J.J.; Leary, M.; Subic, A.; Gibson, M.A. A review of shape memory alloy research, applications and opportunities. Mater. Des. 2014, 56, 1078-1113. [CrossRef]

3. Zhang, Y.; Zhu, S. Seismic response control of building structures with superelastic shape memory alloy wire dampers. J. Eng. Mech. 2008, 134, 240-251. [CrossRef]

4. Qiu, C.X.; Zhu, S. Performance-based seismic design of self-centering steel frames with SMA-based braces. Eng. Struct. 2017, 130, 67-82. [CrossRef]

5. Feng, W.; Fang, C.; Wang, W. Behavior and design of top flange-rotated self-centering steel connections equipped with SMA ring spring dampers. J. Constr. Steel Res. 2019, 159, 315-329. [CrossRef]

6. GB 50010. Code for Seismic Design of Buildings Beijing; China Architecture \& Building Press: Beijing, China, 2010.

7. Abirami, T.; Loganaganandan, M.; Murali, G.; Fediuk, R.; Vickhram, S.R.; Vignesh, T.; Januppriya, G.; Karthikeyan, K. Experimental research on impact response of novel steel fibrous concretes under falling mass impact. Constr. Build Mater. 2019, 222, 447-457. [CrossRef]

8. Murali, G.; Fediuk, R. A taguchi approach for study on impact response of ultra-high-performance polypropylene fibrous cementitious composite. J. Build. Eng. 2020, 30, 101301. [CrossRef]

9. Svintsov, A.P.; Shchesnyak, E.L.; Fediuk, R.S.; Galishnikova, V.V. Monitoring of heating systems as a factor of energy safety of buildings. J. Build. Eng. 2020, 31, 101384. [CrossRef]

10. Wang, W.; Fang, C.; Liu, J. Large size superelastic SMA bars: Heat treatment strategy, mechanical property and seismic application. Smart Mater. Struct. 2016, 25, 075001. [CrossRef]

11. Li, H.N.; Liu, M.M.; Fu, X. An innovative re-centering SMA-lead damper and its application to steel frame structures. Smart Mater. Struct. 2018, 27, 075029. [CrossRef] 
12. Ibragimov, R.; Fediuk, R. Improving the early strength of concrete: Effect of mechanochemical activation of the cementitious suspension and using of various superplasticizers. Constr. Build. Mater. 2019, 226, 839-848. [CrossRef]

13. Lesovik, V.; Voronov, V.; Glagolev, E.; Fediuk, R.; Alaskhanov, A.; Mugahed, Y.H.; Murali, G.; Baranov, A. Improving the behaviors of foam concrete through the use of composite binder. J. Build. Eng. 2020, 31, 101414. [CrossRef]

14. Xue, S.D.; Wang, L.; Zhuang, P. Design and performance study of a SMA incorporated friction damaper. World Earth. Eng. 2006, 22, 1-6. [CrossRef]

15. Ren, W.J.; Wang, L.Q.; Ma, Z.C. Investigation on mechanical behavior of innovative shape memory alloy-friction damper. Jianzhu Jiegou Xuebao 2013, 34, 83-90. [CrossRef]

16. Liu, M.M.; Li, H.N.; Fu, X. Experimental and numerical analysis of an innovative re-centering shape memory alloys-shearing lead damper. Gongcheng Lixue 2018, 35, 52-58. [CrossRef]

17. Huang, Z.; Li, H.N.; Fu, X. Optimum design of a re-centering deformation-amplified SMA damper. Gongcheng Lixue 2018, 36, 202-210. [CrossRef]

18. Hu, S.J.; Gu, Q.; Jiang, J.; Xiong, J.G. Experimental study of the seismic performance for an innovative for an self-centering SMA brace. Gongcheng Lixue 2020. [CrossRef]

19. Lin, Y.H.; Peng, H.H.; Zhang, S. Mechanical behavior of super elastic NiTi wires. Huanan Ligong Daxue Xuebao 2010, 38, 131-135. [CrossRef]

20. Yan, S.; Wang, Q.; Wang, W. Experimental research on mechanical performance for pseudo-elasticity of shape memory alloy. Shenyang Jianzhu Daxue Xuebao 2010, 26, 458-463.

21. Zhou, H.J.; Qi, S.K.; Yao, G.Z. Damping and frequency of a model cable attached with a pre-tensioned shape memory alloy wire: Experiment and analysis. J. Struct. Control Health Monit. 2018, 25, 1-19. [CrossRef]

22. Lin, C.K.; Wang, Z.Q.; Yang, X.; Zhou, H.J. Experimental study on temperature effects on NiTi shape memory alloys under fatigue loading. Materials 2020, 13, 573-586. [CrossRef] [PubMed]

23. Desroches, R.; Mccormick, J.; Delemont, M. Cyclic properties of superelastic shape memory alloy wires and bars. J. Struct. Eng. 2004, 130, 38-46. [CrossRef]

24. Qian, H.; Li, H.N.; Song, G.B. Constitutive model of shape memory alloy based on plastic theory: Experiment and simulation J. Funct. Mater. 2007, 38, 1114-1118. [CrossRef]

25. Wang, J.; Moumni, Z.; Zhang, W. A thermomechanically coupled finite-strain constitutive model for cyclic pseudoelasticity of polycrystalline shape memory alloys. Int. J. Plast. 2017, 97, 194-221. [CrossRef]

26. Xu, X.; Cheng, G.M.; Zheng, J.H. Tests on pretrained superelastic NiTi shape memory alloy rods: Towards application in self-centering link beams. Adv. Civ. Eng. 2018, 2018, 2037376. [CrossRef]

27. Wang, B.; Songye Zhu, S.Y.; Casciati, F. Experimental study of novel self-centering seismic base isolators incorporating superelastic shape memory alloys. J. Struct. Eng. 2020, 146, 04020129. [CrossRef]

28. Graesser, E.J.; Cozzarelli, F.A. Shape memory alloys as new materials for seismic isolation. J. Eng. Mech. 1991, 117, 2590-2608. [CrossRef] 